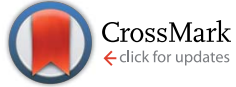

Cite this: Chem. Sci., 2016, 7, 1281

Received 8th October 2015

Accepted 4th November 2015

DOI: $10.1039 / \mathrm{c} 5 \mathrm{sc} 03823 \mathrm{e}$

www.rsc.org/chemicalscience

\section{Sulfoxide-directed metal-free cross-couplings in the expedient synthesis of benzothiophene-based components of materials $\uparrow$}

Andrew J. Eberhart, Harry Shrives, Yuntong Zhang, Amandine Carrër, Adam V. S. Parry, Daniel J. Tate, Michael L. Turner and David J. Procter*

A metal-free approach combining sulfoxide-directed metal-free $\mathrm{C}-\mathrm{H}$ cross-couplings with tuneable electrophile-mediated heterocyclizations and carbocyclative dimerizations, allows expedient access to benzothiophene-based systems that are components of important materials or are proven organic materials in their own right. As benzothiophene-based materials are typically prepared using $\mathrm{Pd}$ catalyzed cross-coupling processes, our approach allows potential issues of metal cost and supply, and metal-contamination of products, to be avoided.

\section{Introduction}

The selective formation of carbon-carbon bonds to aromatic rings is a critical goal in science. ${ }^{1}$ Although the use of first row metals is an important and growing field (e.g. Fe, Co, Ni, Cu), modern cross-coupling technology still typically involves the use of platinum group metals (e.g. $\mathrm{Pd}, \mathrm{Ru}, \mathrm{Rh}, \mathrm{Pt}),{ }^{2}$ and the development of cross-coupling reactions that do not involve the use of an expensive and/or supply-risk metal is highly desirable. $^{3}$ Such processes have additional benefits as trace metal contamination in products arising from metal-catalyzed processes is a concern in industry, particularly the pharmaceutical and organic electronic sectors. ${ }^{4}$ In the latter field, even 'undetectable' levels of palladium contaminant can have a detrimental effect on the electrical properties of materials and thin film device performance. ${ }^{4 d}$

Here we describe an expedient metal-free approach to important benzothiophene-based architectures, including motifs that are crucial components in valuable organic small molecule and polymeric materials (Scheme 1A). ${ }^{5}$ Organic materials are increasingly prepared using $\mathrm{C}-\mathrm{H}$ activation methods mediated by platinum group metals ${ }^{6}$ in addition to cross-couplings using classical Pd-catalyzed methods. ${ }^{7}$ Benzodithiophenes (BDTs) ${ }^{8}$ and napthodithiophenes (NDTs), ${ }^{9}$ in particular, have been exploited in high-performance smallmolecule/oligomeric semi-conducting materials (e.g. 1-4),

School of Chemistry, University of Manchester, Oxford Rd, Manchester, M13 9PL, UK. E-mail: david.j.procter@manchester.ac.uk

$\dagger$ Electronic supplementary information (ESI) available: Full experimental details, NMR spectra, CCDC numbers for X-ray structures, and details of preliminary materials evaluation and device preparation. CCDC 1415330-1415334. For ESI and crystallographic data in CIF or other electronic format see DOI: 10.1039/c5sc03823e polymeric semiconductors, ${ }^{8,9}$ and in co-polymers for solar cells $^{8,9}$ (e.g. 5 and 6) (Scheme 1B).

The crucial benzothiophene-based motifs are typically prepared using Pd-catalyzed cross-coupling processes in one or more key steps. Our approach utilizes sulfoxide-directed metalfree $\mathrm{C}-\mathrm{H}$ cross-coupling processes, ${ }^{10}$ allowing established Pd-catalyzed couplings and associated metal-contamination to be avoided, and new diversity-introducing hetero- and

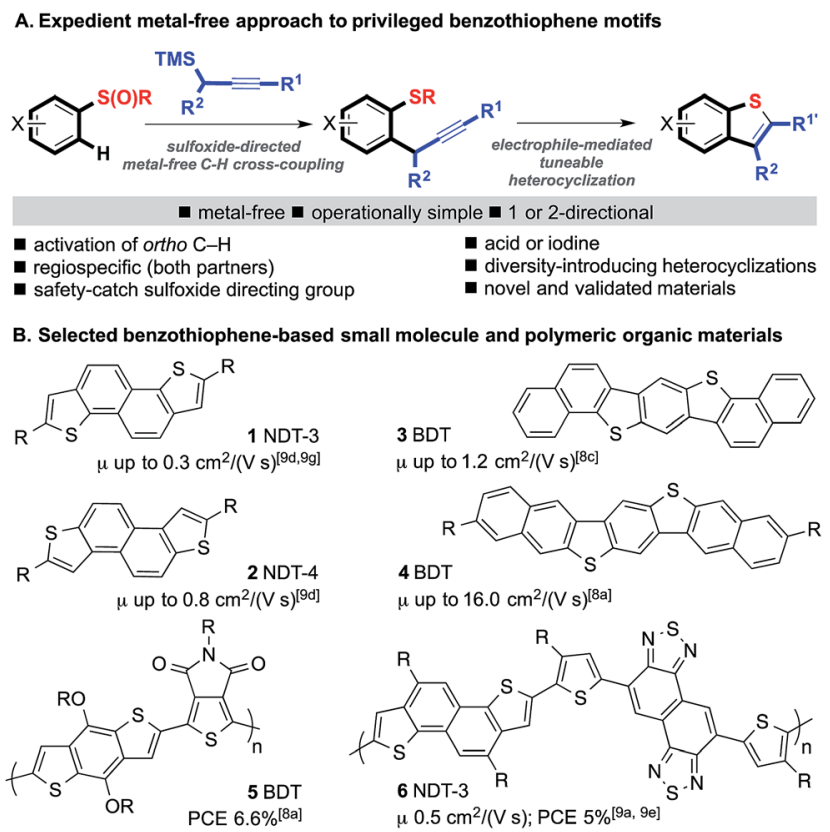

Scheme 1 (A) Short metal-free approach to privileged benzothiophenes. (B) Benzothiophene-based organic materials. NDT = napthodithiophene; BDT = benzodithiophene; $\mu$ = electron mobility; PCE = Power Conversion Efficiency. 
carbocyclizations mediated by electrophiles. The novel approach has been used in the metal-free synthesis of a range of benzothiophenes including components of materials, and both validated organic materials and previously unknown organic materials for evaluation.

\section{Results and discussion}

\section{A two-directional, metal-free route to NDT materials}

We began by exploring the conversion of the products of our sulfoxide-directed, metal-free, propargylative $\mathrm{C}-\mathrm{H}$ crosscoupling $^{10}$ to benzothiophenes. Pleasingly, straight-forward variation of iodine or acid-mediated conditions $(\mathrm{A}-\mathrm{C})$ allowed access to a wide range of decorated benzothiophene motifs bearing different levels of oxidation at the carbon adjacent to the benzothiophene ring (Scheme 2). ${ }^{11}$ In addition, a wide range of substituents on the aromatic ring are tolerated thus allowing the electronic properties of target materials to be tuned (vide infra).

A proposed mechanism for the formation of benzothiophenes under iodine-mediated conditions $\mathrm{A}-\mathrm{C}$ is set out in Scheme 3. Upon treatment with iodine, cyclization gives sulfonium salts I that undergo demethylation and tautomerization to form common iodide intermediates II. Upon heating, homolysis gives radicals III that either undergo quenching with $\mathrm{O}_{2}$ (conditions A) to give ketone products, possibly via alkylhydroperoxide intermediates IV, or with 1,4-cyclohexadiene (conditions B) to give

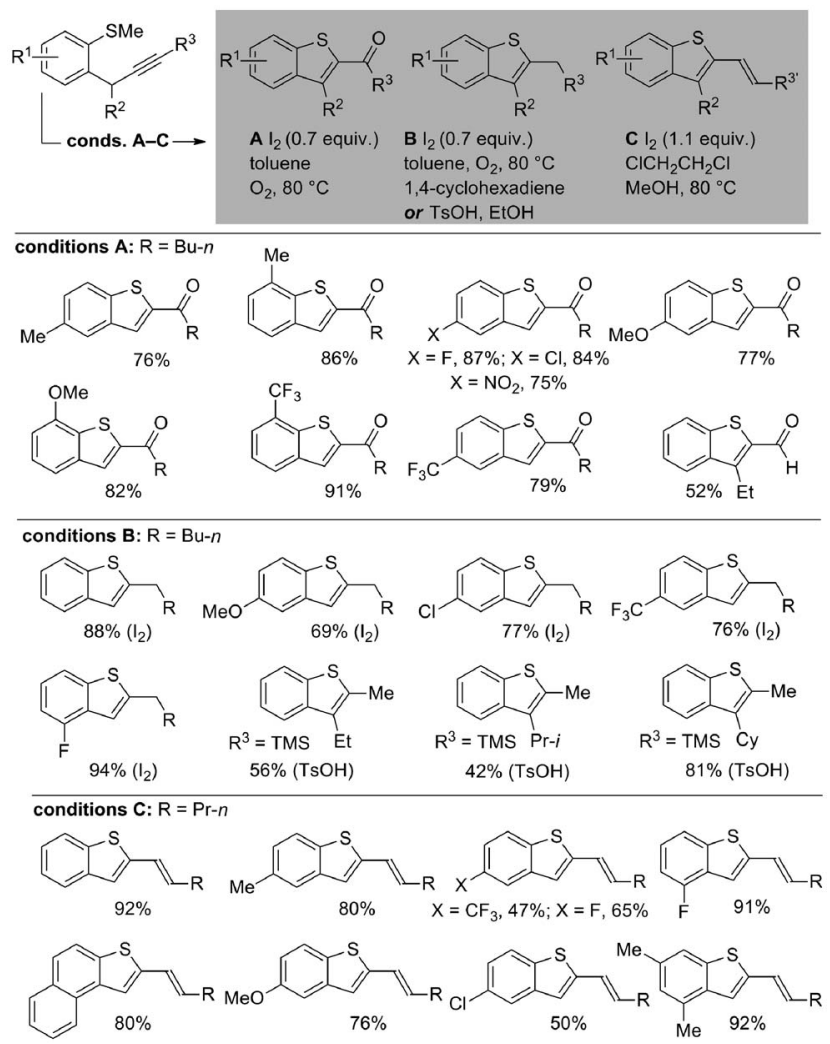

Scheme 2 Tuneable electrophile-mediated, heterocyclization to give decorated benzothiophenes (isolated yields after purification).

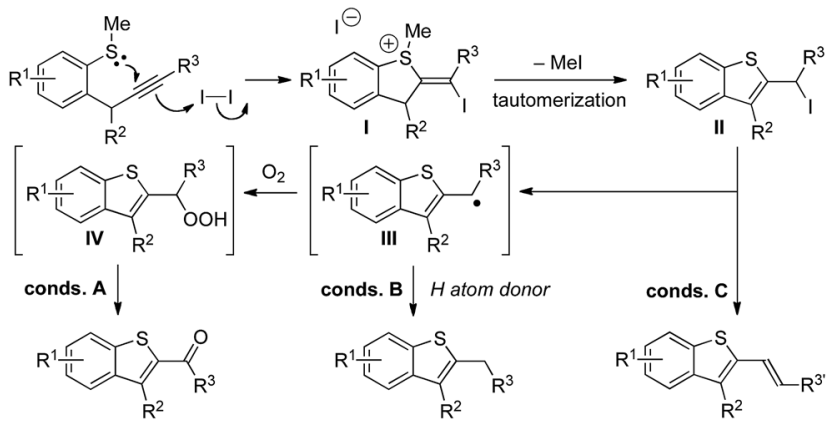

Scheme 3 Proposed mechanism for the tuneable iodine-mediated, heterocyclization to give decorated benzothiophenes.

alkyl substituted benzothiophene products. Under conditions C, elimination of iodides II gives alkenyl benzothiophene products. Acid-mediated cyclization (alternative conditions B) gives alkyl substituted benzothiophene products directly after demethylation of sulfonium salt intermediates.

We next investigated the feasibility of combining sulfoxidedirected cross-coupling with electrophile-mediated heterocyclizations in metal-free approaches to benzothiophene-based components of organic materials. We first examined a metalfree, two-directional synthesis of naphthodithiophene (NDT) motifs, typically prepared using Pd-catalyzed Sonogashira couplings, ${ }^{9 d, g}$ and found in high performance small molecule and polymeric organic materials. ${ }^{9}$ Bis-sulfoxide starter units 7 and $\mathbf{8}$, readily-prepared from 2,6-dihydroxynapthalene ( $82 \%, 2$ steps) and 1,5-dihydroxynapthalene $(66 \%, 2$ steps $)\left(n-\mathrm{C}_{6} \mathrm{H}_{13} \mathrm{SH}\right.$, toluene, Dean-Stark; $\left.m \mathrm{CPBA}, \mathrm{CH}_{2} \mathrm{Cl}_{2}\right),{ }^{12}$ underwent two-directional metal-free $\mathrm{C}-\mathrm{H}$ propargylation, under our previously reported conditions, ${ }^{10}$ to deliver adducts $\mathbf{9}$ and $\mathbf{1 0}$ in high yield (Scheme 4). In the cross-coupling to give 9, complete regiocontrol is observed. The process proved scalable and the crosscoupling of 8 gave $\mathbf{1 0 b}$ in $76 \%$ on a $1.5 \mathrm{~g}$ scale.

Further diversity can be introduced by tuning the conditions of the subsequent two-directional heterocyclization. For example, while acid-mediated cyclization of $\mathbf{9}$ and 10b (variant

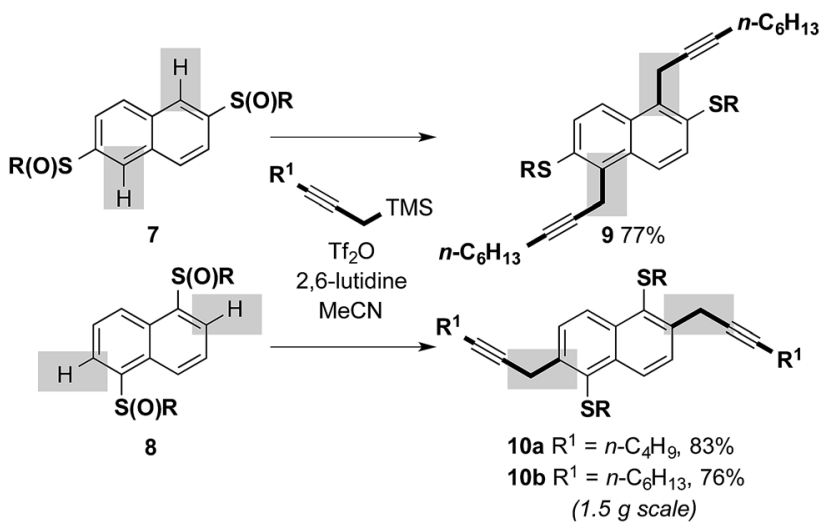

Scheme 4 Two-directional, sulfoxide-directed, metal-free crosscouplings involving substrates derived from dihydroxynaphthalenes; $\mathrm{R}=n-\mathrm{C}_{6} \mathrm{H}_{13}$ (isolated yields after purification). 
of conditions B; the use of NaI facilitates demethylation of sulfur in an intermediate sulfonium salt; Schemes 2 and 3) delivers alkyl-substituted materials 11 and 12, respectively, iodine-mediated cyclization delivers acyl-substituted materials 13 and 14 (all 2 steps from sulfoxide). Furthermore, iodinemediated cyclization of $\mathbf{9}$ and $\mathbf{1 0 b}$ under eliminative conditions gave alkenylated products 15 and 16 (Scheme 5). NDT products 11-16 are potential small molecule organic materials in their own right (vide infra) ${ }^{\mathbf{9 d}, g}$ and 11-14 were characterized by X-ray crystallographic analysis (Fig. 1). ${ }^{13}$ Thus, sulfoxide-directed cross-couplings allow palladium-mediated couplings to be avoided in the four-step synthesis of validated (11 and 12) and unexplored (13-16) types of organic material.

\section{A metal-free route to BDT materials}

Attractively, the sulfoxide moiety in our approach can be viewed as a 'safety-catch' directing group: only upon oxidation to the sulfoxide is the substrate receptive to cross-coupling. Furthermore, the directing group is reduced during the coupling, the directing effect is 'switched-off', and over-alkylation is impossible. ${ }^{10 b}$ Selective coupling in bis-sulfide substrates bearing latent directing groups is therefore possible provided selective oxidation can be achieved. For example, symmetrical bis-sulfide starter unit 17 and intermediate 19 can be selectively activated and thus undergo selective metal-free cross-coupling. This allows the controlled metal-free construction of unsymmetrical
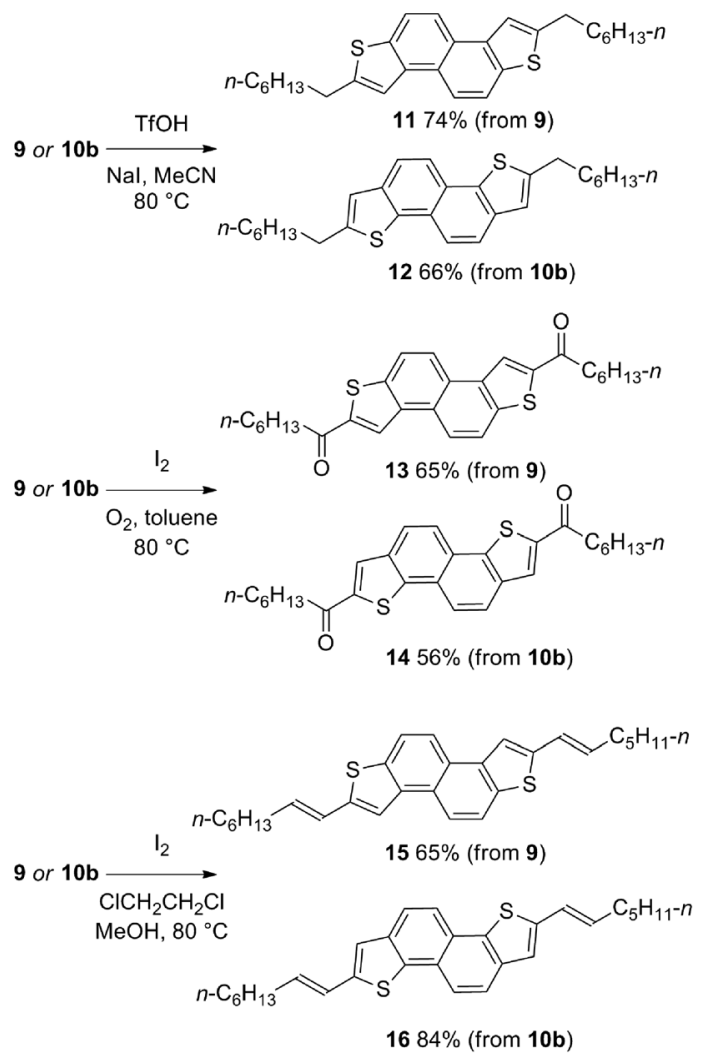

Scheme 5 'Tuneable' 2-directional heterocyclizations for the metalfree synthesis of NDT materials (isolated yields after purification).

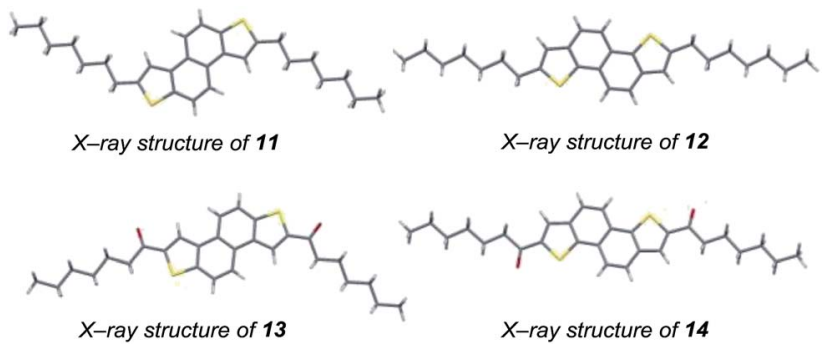

Fig. 1 X-ray crystallographic analysis of materials 11-14.

targets such as BDT 21 using iterative sulfoxide-directed crosscoupling (Scheme 6). The ability to prepare unsymmetrical small-molecule materials is crucial for several applications including the immobilization of materials on surfaces in the exploitation of self-assembled monolayers (SAM) in organic electronic devices. ${ }^{\mathbf{1 4}}$

We next addressed the challenge of developing a short, metalfree synthesis of extended BDT motifs. Such motifs are typically prepared by Pd-catalyzed Sonogashira, Suzuki, or Negishi couplings. ${ }^{8}$ Tuning the heterocyclization of the products from metal-free cross-coupling delivers benzothiophenes bearing conjugated alkenes (Scheme 2, conditions C). Subsequent, unprecedented iodine-mediated, carbocyclative dimerization conveniently delivers novel, substituted benzodithiophenes 22-28 in moderate to excellent yield ( 3 steps overall from sulfoxide). The structure of 22 was confirmed by X-ray crystallography. ${ }^{13}$ Crucially, the alkyl substituents on the central benzene ring, and the electronic properties of the flanking benzene rings, can be readily varied through judicial choice of propargylsilane and sulfoxide coupling partners in the metal-free approach (Scheme 7A). A proposed mechanism for the novel dimerization is shown in Scheme 7B: homocoupling of the activated alkene $\mathbf{2 9}$ followed by acid-mediated cyclization gives intermediate 30 en route to dimers 22-28.

We have carried out preliminary evaluation of the materials prepared. Cyclic voltammetry and UV/Vis spectroscopy were

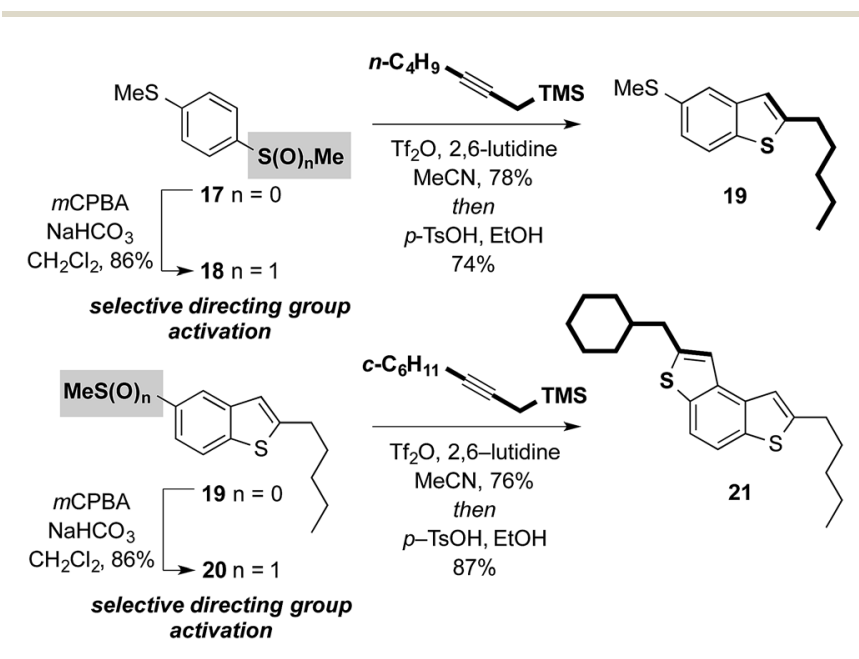

Scheme 6 'Safety-catch' sulfoxide directing groups in metal-free cross-couplings: potential for the selective synthesis of unsymmetrical benzothiophene-based components. 


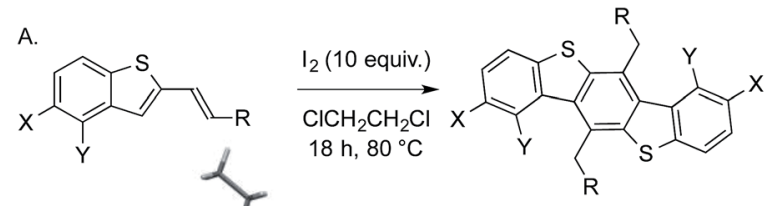

$22 \mathrm{X}=\mathrm{Y}=\mathrm{H}, \mathrm{R}=\mathrm{Pr}-n, 86 \%$ $23 \mathrm{X}=\mathrm{Me}, \mathrm{Y}=\mathrm{H}, \mathrm{R}=\mathrm{Pr}-n, 63 \%$ $24 \mathrm{X}=\mathrm{OMe}, \mathrm{Y}=\mathrm{H}, \mathrm{R}=\mathrm{Pr}-n, 55 \%$ $25 X=H, Y=F, R=\operatorname{Pr}-n, 43 \%$ $26 \mathrm{X}=\mathrm{F}, \mathrm{Y}=\mathrm{H}, \mathrm{R}=\operatorname{Pr}-n, 58 \%$ $27 \mathrm{X}=\mathrm{Cl}, \mathrm{Y}=\mathrm{H}, \mathrm{R}=\operatorname{Pr}-n, 64 \%$ $28 \mathrm{X}=\mathrm{Y}=\mathrm{H}, \mathrm{R}=$ Pent $-n, 81 \%$

B.

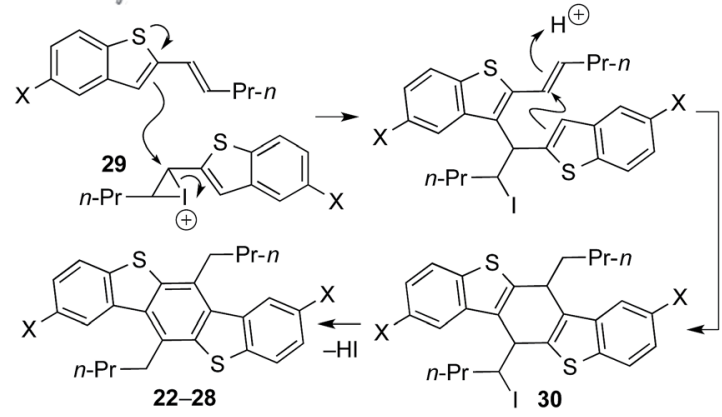

Scheme 7 (A) Carbocyclative dimerization in a metal-free approach to novel dialkyl-substituted benzodithiophenes (BDTs). (B) Proposed mechanism for the dimerization.

used to determine the HOMO/LUMO levels and energy gaps for compounds 11-16 and 22-28. In particular, compounds 11-14 showed a low lying HOMO of $<-5.5 \mathrm{eV}$ and energy band gap greater than $3 \mathrm{eV}$, consistent with previous reports suggesting the orientation of the thiophene ring has little effect on the electronic structure of the core. ${ }^{\boldsymbol{9} \boldsymbol{h}}$ As expected, a lowering of the HOMO/LUMO was observed for the acyl-substituted derivatives.

Thin films of compounds 11-14 were characterised using $\mathrm{X}$ ray diffraction and atomic force microscopy, and organic field effect transistors (OFETs) were prepared and analysed using the conventional thin film transistor techniques. ${ }^{15}$ Consistent with previous observations, ${ }^{9 \boldsymbol{d}, \boldsymbol{g}, \boldsymbol{h}}$ novel materials $\mathbf{1 1}$ and 13 formed smooth thin films and demonstrated p-type (hole transporting) behaviour in a field effect transistor. In particular, compound 11 demonstrated a mobility of $0.2 \mathrm{~cm}^{2} \mathrm{~V}^{-1} \mathrm{~s}^{-1}$, high current on/ off ratio of $10^{7}$ and a threshold voltage of $-22 \mathrm{~V}$ over an average of 9 devices. This performance is consistent with those reported for fused benzothiophene semiconductors. ${ }^{9 h}$

\section{Conclusions}

In conclusion, a metal-free approach allows expedient access to benzothiophene-based systems that are components of important materials or are proven organic materials in their own right. The approach combines sulfoxide-directed metalfree $\mathrm{C}-\mathrm{H}$ cross-couplings with novel tuneable electrophilemediated heterocyclizations and carbocyclative dimerizations. As benzothiophene-based materials are typically prepared using Pd-catalyzed cross-coupling processes, our approach allows potential issues of metal cost and supply, and the metal-contamination of products, to be avoided.

\section{Acknowledgements}

We thank the EPSRC (Established Career Fellowship to D. J. P. and Doctoral Prize to A. J. E), The Leverhulme Trust (Research Fellowship to D. J. P), and Novartis (Studentship to H. S.).

\section{Notes and references}

1 (a) S. D. Roughley and A. M. Jordan, J. Med. Chem., 2011, 54, 3451; (b) J. Magano and J. R. Dunetz, Chem. Rev., 2011, 111, 2177; (c) Transition Metal-Catalyzed Couplings in Process Chemistry: Case Studies From the Pharmaceutical Industry, ed. J. Magano and J. R. Dunetz, Wiley, 2013; (d) C. Toberg and M. Beller, Adv. Synth. Catal., 2009, 351, 3027.

2 For recent reviews, see: (a) P. B. Arockiam, C. Bruneau and P. H. Dixneauf, Chem. Rev., 2012, 112, 5879; (b) J. WencelDelord, T. Dröge, F. Liu and F. Glorius, Chem. Soc. Rev., 2011, 40, 4740; (c) D. A. Colby, R. G. Bergman and J. A. Ellman, Chem. Rev., 2010, 110, 624; (d) T. W. Lyons and M. S. Sanford, Chem. Rev., 2010, 110, 1147; (e) X. Chen, K. M. Engle, D. Wang and J.-Q. Yu, Angew. Chem., Int. Ed., 2009, 48, 5094.

3 For recent metal-free cross-coupling approaches based on Pummerer-type processes, see: (a) T. Kobatake, D. Fujino, S. Yoshida, H. Yorimitsu and K. Oshima, J. Am. Chem. Soc., 2010, 132, 11838; (b) T. Kobatake, S. Yoshida, H. Yorimitsu and K. Oshima, Angew. Chem., Int. Ed., 2010, 49, 2340; (c) A. J. Eberhart, J. E. Imbriglio and D. J. Procter, Org. Lett., 2011, 13, 5882; (d) Y. Ookubo, A. Wakamiya, H. Yorimitsu and A. Osuka, Chem.-Eur. J., 2012, 18, 12690; (e) A. J. Eberhart, C. Cicoira and D. J. Procter, Org. Lett., 2013, 15, 3994; (f) K. Murakami, H. Yorimitsu and A. Osuka, Angew. Chem., Int. Ed., 2014, 53, 7510; $(g)$ X. Huang and N. Maulide, J. Am. Chem. Soc., 2011, 133, 8510; (h) X. Huang, M. Patil, C. Fares, W. Thiel and N. Maulide, J. Am. Chem. Soc., 2013, 135, 7312; (i) B. Peng, D. Geerdink, C. Farés and N. Maulide, Angew. Chem., Int. Ed., 2014, 53, 5462; (j) B. Peng, X. Huang, L.-G. Xie and N. Maulide, Angew. Chem., Int. Ed., 2014, 53, 8718. For selected reviews of the Pummerer reaction, see: $(k)$ L. H. S. Smith, S. C. Coote, H. F. Sneddon and D. J. Procter, Angew. Chem., Int. Ed., 2010, 49, 5832; (l) S. Akai and Y. Kita, Top. Curr. Chem., 2007, 274, 35; (m) K. S. Feldman, Tetrahedron, 2006, 62, 5003; (n) S. K. Bur and A. Padwa, Chem. Rev., 2004, 104, 2401.

4 For reviews on palladium removal, see: $(a)$ C. E. Garrett and K. Prasad, Adv. Synth. Catal., 2004, 346, 889. See also ref. $1 c$. (b) K. Königsberger, G.-P. Chen, R. R. Wu, M. J. Girgis, K. Prasad, O. Repič and T. J. Blacklock, Org. Process Res. Dev., 2003, 7, 733. For a recent example of the negative impact of metal impurities, see: (c) J. C. Hermann, Y. Chen, C. Wartchow, J. Menke, L. Gao, S. K. Gleason, N.-E. Haynes, N. Scott, A. Petersen, S. Gabriel, B. Vu, K. M. George, A. Narayanan, S. H. Li, H. Qian, N. Beatini, 
L. Niu and Q.-F. Gan, ACS Med. Chem. Lett., 2013, 4, 197. For an example of the palladium contamination of large organic molecules and polymers, see: (d) K. T. Nielsen, K. Bechgaard and F. C. Krebs, Macromolecules, 2005, 38, 658. See also ref. $7 d$ and $e$.

5 For recent reviews on thiophene-based organic materials, see: (a) K. Takimiya and I. Osaka, Chem. Rec., 2015, 15, 175; (b) K. Takimiya, I. Osaka, T. Mori and M. Nakano, Acc. Chem. Res., 2014, 47, 1493; (c) K. Takimiya, S. Shinamura, I. Osaka and E. Miyazaki, Adv. Mater., 2011, 23, 4347.

6 For recent reviews, see: (a) Y. Segawa, T. Maekawa and K. Itami, Angew. Chem., Int. Ed., 2015, 54, 66; (b) A. Facchetti, L. Vaccaro and A. Marrocchi, Angew. Chem., Int. Ed., 2012, 51, 3520.

7 (a) Palladium-Catalyzed Coupling Reactions: Practical Aspects and Future Developments, ed. A. Molnar, Wiley, 2013; (b) J. Tsuji, Palladium Reagents and Catalysts: New Perspectives for the 21st Century, Wiley, Sussex, England, 2004; (c) E. Negishi, and A. de Meijere, Handbook of Organopalladium Chemistry for Organic Synthesis, Wiley, New York, 2002. For specific application in organic materials synthesis, see for example; (d) G. Marzano, C. V. Ciasca, F. Babudri, G. Bianchi, A. Pellegrino, R. Po and G. M. Farinol, Eur. J. Org. Chem., 2014, 6583; (e) B. Carsten, F. He, H. J. Son and T. X. L. Yu, Chem. Rev., 2011, 111, 1493.

8 For selected references on BDTs, see: (a) C. Mitsui, T. Okamoto, M. Yamagishi, J. Tsurumi, K. Yoshimoto, K. Nakahara, J. Soeda, Y. Hirose, H. Sato, A. Yamano, T. Ueura and J. Takeya, Adv. Mater., 2014, 26, 4546; (b) C. Cabanetos, A. El Labban, J. A. Bartelt, J. D. Douglas, W. R. Mateker, J. M. J. Fréchet, M. D. McGhee and P. M. Beaujuge, J. Am. Chem. Soc., 2013, 135, 4656; (c) Y. Chen, H. Chang, H. Tian, C. Bao, W. Li, D. Yan, Y. Geng and F. Wang, Org. Electron., 2012, 13, 3268; (d) T. Kashiki, S. Shinamura, M. Kohara, E. Miyazaki, K. Takimiya, M. Ikeda and H. Kuwabara, Org. Lett., 2009, 11, 2473; (e) P. Gao, D. Beckmann, H. N. Tsao, X. Feng, V. Enkelmann, W. Pisula and K. Müllen, Chem. Commun., 2008, 1548; $(f)$ H. Ebata, E. Miyazaki, T. Yamamoto and K. Takimiya, Org.
Lett., 2007, 9, 4499; $(g)$ K. Takimiya, Y. Honda, H. Ebata, N. Niihara and T. Otsubo, J. Org. Chem., 2005, 70, 10569. See also ref. 5 .

9 For selected references on NDTs, see: (a) I. Osaka, T. Kakara, N. Takemura, T. Koganezawa and K. Takimiya, J. Am. Chem. Soc., 2013, 135, 8834; (b) S. Shi, X. Xie, P. Jang, S. Chen, L. Wang, M. Wang, H. Wang, X. Li, G. Yu and Y. Li, Macromolecules, 2013, 46, 3358; (c) C. Viglianisi, L. Becucci, C. Faggi, S. Piantini, P. Procacci and S. Menichetti, J. Org. Chem., 2013, 78, 3496; (d) I. Osaka, S. Shinamura, T. Abe and K. Takimiya, J. Mater. Chem. C, 2013, 1, 1297; (e) I. Osaka, T. Abe, M. Shimawaki, T. Koganezawa and K. Takimiya, ACS Macro Lett., 2012, 1, 437; (f) S. Loser, H. Miyauchi, J. W. Hennek, J. Smith, C. Huang, A. Facchetti and T. J. Marks, Chem. Commun., 2012, 48, 8511; $(g)$ S. Shinamura, E. Miyazaki and K. Takimiya, $J$. Org. Chem., 2010, 75, 1228; (h) S. Shinamura, I. Osaka, E. Miyazaki, A. Nakao, M. Yamagishi, J. Takeya and K. Takimiya, J. Am. Chem. Soc., 2011, 133, 5024. See also ref. 5.

10 (a) A. J. Eberhart and D. J. Procter, Angew. Chem., Int. Ed., 2013, 52, 4008; (b) A. J. Eberhart, H. J. Shrives, E. Álvarez, A. Carrër, Y. Zhang and D. J. Procter, Chem.-Eur. J., 2015, 21, 7428. For an application of the metal-free coupling, see: (c) T. Sugahara, K. Murakami, H. Yorimitsu and A. Osuka, Angew. Chem., Int. Ed., 2014, 53, 9329.

11 For reviews of $\mathrm{I}_{2}$-mediated cyclizations, see: (a) P. T. Parvatkar, P. S. Parameswaran and S. G. Tilve, Chem.Eur. J., 2012, 18, 5460; (b) A. Palisse and S. F. Kirsch, Org. Biomol. Chem., 2012, 10, 8041; (c) B. Godoi, R. F. Schumacher and G. Zeni, Chem. Rev., 2011, 111, 2937. $12 \mathrm{ESI}^{\dagger}$

$13 \mathrm{ESI} \dagger$

14 (a) For a review, see: M. Halik and A. Hirsch, Adv. Mater., 2011, 23, 2689; (b) For a recent example, see: A. V. S. Parry, K. Lu, D. J. Tate, B. Urasinska-Wojcik, D. Caras-Quintero, L. A. Majewski and M. L. Turner, Adv. Funct. Mater., 2014, 24, 6677 .

$15 \mathrm{ESI} \dagger$ 